\title{
Perceived structure and achievement goals as predictors of students' self-regulated learning and affect and the mediating role of competence need satisfaction
}

\author{
Athanasios Mouratidis ${ }^{\mathrm{a}, *}$, Maarten Vansteenkiste ${ }^{\mathrm{b}}$, Aikaterini Michou ${ }^{\mathrm{c}}$, Willy Lens ${ }^{\mathrm{d}}$ \\ a University of Leuven, Faculty of Psychology and Educational Studies, Tiensestraat 102, B-3000 Leuven, Belgium \\ b Ghent University, H. Dunantlaan 2, 9000 Gent, Belgium \\ c Bilkent University, Graduate School of Education, Main Campus-G Building, 06800, Bilkent, Ankara, Turkey \\ d University of Leuven, Department of Psychology, Tiensestraat 102, B 3000 Leuven, Belgium
}

\section{A R T I C L E I N F O}

\section{Article history:}

Received 3 October 2011

Received in revised form 10 August 2012

Accepted 2 September 2012

\section{Keywords:}

Perceived structure

Achievement goals

Self-regulated learning

Affect

Adolescents

\begin{abstract}
A B S T R A C T
We investigated the extent to which perceived structure and personal achievement goals could explain students' effective learning strategies and affect-related experiences in a sample of Greek adolescent students $(N=606 ; 45.4 \%$ males; mean age: $M=15.05, S D=1.43)$. Having controlled for students' social desirability responses, we used multilevel analyses, and found that between-student (i.e., within class) differences in perceived structure related positively to learning strategies and positive affect and negatively to negative affect, with the relations being partially mediated by competence need satisfaction. In addition, we found between-student differences in the relations of mastery-approach, performance-approach, and performanceavoidance goals to the learning-strategy and affect outcomes. Moreover, at the between-class level, perceived structure related positively to learning strategies and positive affect, and negatively to depressive feelings. Finally, an interesting cross-level interaction between perceived structure and performance-avoidance goals for negative affect revealed that well-structured classrooms attenuated the positive, harmful relation between performance-avoidance goals and negative affect. These findings indicate the key role of structure and the endorsement of mastery-approach goals in the classroom.
\end{abstract}

(c) 2012 Elsevier Inc. All rights reserved.

\section{Introduction}

Undoubtedly, classrooms characterized by appropriate support and guidance facilitate desired academic outcomes (Jang, Reeve, \& Deci, 2010; Reeve, 2006) and the same seems true for students' endorsement of mastery-approach goals (Brophy, 2005; Elliot, 2005). However, it is unclear to what extent the learning environment of the classroom and students' endorsement of achievement goals independently (or interactively) predict outcomes, such as students' learning strategies and school-related affect. This research question has received some empirical attention. Research conducted from the achievement goal perspective has investigated the classroom environment according to how students perceive their teacher to promote particular achievement goals during daily classroom activities (e.g., Kaplan, Middleton, Urdan, \& Midgley, 2002). However, as Urdan and Schoenfelder (2006) pinpointed, it remains unclear to what degree students' personal achievement goals "color" their

\footnotetext{
* Corresponding author at: Faculty of Psychology and Educational Studies, Tiensestraat 102, B 3000 Leuven, Belgium.

E-mail addresses: Thanasis.Mouratidis@ppw.kuleuven.be (A. Mouratidis), Maarten.Vansteenkiste@ugent.be (M. Vansteenkiste), aiki.michou@bilkent.edu.tr (A. Michou),Willy.Lens@psy.kuleuven.be (W. Lens).
}

perceptions about which goals are promoted by the teacher during everyday classroom activities.

In the present research, we relied on the notion of structure, as defined in Self-Determination Theory (SDT; Deci \& Ryan, 2000; see also Skinner \& Belmont, 1993), to more validly examine the independent and any likely interactive relations between classroom learning environment and personal achievement goals in the prediction of school-related outcomes. We defined and operationalized structure as the extent to which a teacher helps his or her students selfregulate their behavior to become (or remain) task-engaged by providing clear expectations, explicit directions, and appropriate guidance (Jang et al., 2010).

We have three main reasons for focusing on structure in conjunction with achievement goals when studying the learning environment of the classroom. First, both structure and achievement goals refer to competence. Structured classrooms are those that are said to be competence supportive (Skinner \& Belmont, 1993), while achievement goals are conceptualized depending on how competence is defined and valenced (Elliot, 2005). Moreover, studying structure in conjunction with achievement goals is meaningful because it jointly examines some of the basic premises from two well-validated motivational frameworks, SDT (Deci \& Ryan, 2000) and the achievement goal perspective (Elliot, 2005). Second, provision of structure as a classroom characteristic has been relatively 
understudied (Farkas \& Grolnick, 2010). For instance, although structure has been linked with outcomes such as more self-regulated learning (Sierens, Vansteenkiste, Goossens, Soenens, \& Dochy, 2009), less problem behavior (Vansteenkiste et al., in press), and more active class engagement (Jang et al., 2010), its relation with class-related emotional experiences remains unknown. More importantly, except Jang et al.'s (2010) work, structure has hardly been studied as a between-classroom characteristic. Third, structure is said to relate to adaptive outcomes because it satisfies the need for competence (Seidel, Rimmele, \& Prenzel, 2005; Skinner \& Belmont, 1993), but this hypothesis remains largely untested in the SDT literature. The present study aimed to fill these gaps by employing a multilevel design, conceptualizing achievement goals as pure aims (Elliot, 2005), and taking into account students' potentially biased responses (i.e., social desirability).

\subsection{Perceived structure}

Structure pertains to the degree to which teachers provide the necessary information, cues, prompts, and examples, as well as the needed help, guidance, and feedback, so that students feel competent to attain what is expected of them (Reeve, 2006). Teachers who provide structure set clear rules, provide cause-effect rationales for such rules, communicate their expectations and rules in a clear manner, behave in a contingent way, and utilize teaching practices which are responsive, helpful, and supportive (Skinner, Zimmer-Gembeck, \& Connell, 1998). Specifically in regard to teaching practices, Jang et al. (2010) have summarized that teachers usually rely on three types of instructional practices to establish the above components of structure. First, they outline the framework within which their students are expected to act by providing clear, detailed, and easily understood directions. In this way, teachers facilitate students' successful regulation of their daily class-related activities. Second, they supply a course of action to their students to guide them during daily task engagement. They support students step-by-step through appropriate instructional support, such that students feel capable of achieving their learning objectives. Third, they provide informational competence-related feedback, thereby helping their students realize their actual potential and the steps they need to take to further develop their skills. In sum, all the above teaching practices are thought to set up a well-structured learning environment wherein students have opportunities to fulfill their need for competence (Skinner et al., 1998; see also Farkas \& Grolnick, 2010).

In contrast, lack of structure leads to a permissive, laissez-faire, and even chaotic learning environment. When structure is absent, students have difficulty knowing what is expected from them and may experience their teacher as unhelpful and inconsistent. As students in chaotic environments feel less capable and sure of how to proceed, they are less likely to become (or remain) task-engaged and to exhibit positive emotionality (Reeve, 2006; Skinner et al., 1998). As the few correlational (e.g., Sierens et al., 2009), observational (e.g., Jang et al., 2010; Seidel et al., 2005), and interventional (e.g., Tessier, Sarrazin, \& Ntoumanis, 2010) studies have evidenced, structure is linked with many desired outcomes, including active class engagement, self-determined motivation, and use of high quality cognitive processes.

In our research we aimed to extend this limited body of work by examining structure at both the between-student and betweenclass level. Specifically, at the between-student level, we examined whether perceived structure relates positively to learning and positive affectivity, and whether competence need satisfaction can account for (i.e., mediate) these relationships. At the betweenclassroom level, we examined whether structure can explain any differences in learning outcomes between students belonging to different classes, and whether perceived structure at the class level would be especially beneficial for students endorsing particular achievement goals. Before discussing the latter hypothesis in greater detail, we briefly discuss the different achievement goals and their effects on educational outcomes.

\subsection{Achievement goals, learning strategies, and affect}

Within the achievement goal tradition, four types of achievement goals have been delineated (Elliot \& McGregor, 2001). Masteryapproach goals represent goals focusing on self-improvement or mastering a task; performance-approach goals represent one's aim at outperforming others, whereas performance-avoidance goals reflect one's aim at avoiding being worse than others. Finally, masteryavoidance goals mirror one's strivings to avoid learning less than one possibly could or performing worse than he or she did in the past. Because mastery-avoidance goals are more likely to be endorsed by elderly people (Ciani \& Sheldon, 2010; Elliot, 1999), they are not considered in the present research.

Numerous studies have shown that mastery-approach goals are associated with a host of positive outcomes, including intrinsic motivation, deep-level cognitive processing, meta-cognitive regulation, and positive affect (Hulleman, Schrager, Bodmann, \& Harackiewicz, 2010). These relations come as no surprise because masteryapproach goals are assumed to fuel intrinsic interest and curiosity; they thus represent goals in which learning and improvement is of primary focus. In contrast, performance-avoidance goals are rather maladaptive, as they seem to divert students' attention away from self-regulated learning and self-improvement, and toward concerns about avoiding unfavorable social comparisons. Consequently, performance-avoidance goals are more likely to be associated with less effective learning strategies (e.g., Diseth \& Kobbeltvedt, 2010) and more negative affect (e.g., anxiety; see Elliot \& McGregor, 2001).

Regarding performance-approach goals, research has revealed a blurred picture (Elliot \& Moller, 2003), likely because of the dual nature of performance-approach goals. That is, performance-approach goals concurrently entail an approach tendency (and thus an appetitive form of motivation, see Elliot, 2005) as well as social comparison processes. Therefore, although performance-approach goals do orient students towards success, they are less likely, compared to masteryapproach goals, to facilitate deep-level learning (Harackiewicz, Durik, Barron, Linnenbrink-Garcia, \& Tauer, 2008) and to invoke positive emotions during engagement in learning activities (Elliot \& Moller, 2003).

One likely reason for the sometimes inconsistent findings that concern performance-approach goals may lie in the potentially moderating role of the learning environment (Barron \& Harackiewicz, 2003). Therefore, in our study, we also examined to what extent achievement goals and students' perceptions of structure interact in the prediction of self-regulated learning and affect. Specifically, we explored two alternative patterns of relations. We investigated whether structured learning environments would (a) be even more helpful for students endorsing approach goals, presumably because in a well-structured classroom students with a tendency to approach success may feel even more competent to attain their goals; or (b) attenuate the negative relationship between avoidance goals and positive outcomes, presumably because in highly structured classrooms students with performance-avoidance goals would feel less incompetent than they otherwise would feel in ill-structured classrooms; these students thus might especially benefit from a well-structured classroom.

\subsection{Present research}

We aimed to investigate the relations among achievement goals, perceived structure, learning strategies, and affective experiences in 
the classroom. Instead of examining structure solely as a betweenclassroom (e.g., Seidel et al., 2005) or within-classroom characteristic (thus reflecting between-student differences; e.g., Sierens et al., 2009), we considered it at both the classroom and student level. We formulated five hypotheses and one research question.

Hypothesis 1. We expected that students who perceived their teacher as providing structure would report more use of learning strategies and positive affectivity, most likely because they have better opportunities to satisfy their need for competence (Skinner et al., 1998).

Hypothesis 2. We expected that perceived structure would relate to competence need satisfaction, which in turn would relate to the studied outcomes (mediation hypothesis). ${ }^{1}$

Hypothesis 3. We expected that mastery-approach and performanceapproach goals would be positive predictors, and performanceavoidance goals would be negative predictors, of learning strategies and positive affectivity.

Hypothesis 4. We expected that relative to performance-approach goals, mastery-approach goals would be stronger predictors of these outcomes because mastery-approach goals are more inherently tied to intrinsic motivation and interest (Harackiewicz et al., 2008), and thus more reliable predictors of effective learning strategies and positive affectivity.

Hypothesis 5. We anticipated, aligned with previous research (e.g., Tessier et al., 2010), that students belonging to well-structured classrooms would report higher levels of effective learning strategies and positive affectivity than students belonging to poorly-structured classrooms.

Research question 1. We explored the extent to which achievement goals and perceived structure interact in the prediction of studied outcomes. Finally, we controlled for students' social desirability when testing the above hypotheses and research question.

\section{Method}

\subsection{Participants and procedures}

Participants were 606 (45.4\% males) middle and high school students (mean age $M=15.05, S D=1.43$ ) belonging to 32 classes in five schools located in the metropolitan area of Athens, Greece. The study was approved by the Greek Pedagogical Institute and a written consent from students' parents was obtained. Students completed the questionnaire during a class group session after a research assistant briefly informed the students about the scope of the study. The assistant underscored that participation was voluntary, that there were no right or wrong answers, and that their responses would remain confidential. All students chose to participate. All the questionnaires except depressive feelings were contextualized according to the specific subject matter of each class (either mathematics $[n=22]$ or Greek language $[n=10])$. Unless otherwise mentioned, all the items were answered on a five-point Likert-type scale ranging from 1 (Not at all true of me) to 5 (Totally true of me).

\subsection{Measures}

\subsubsection{Competence need satisfaction}

Five items from the perceived competence subscale of the Intrinsic Motivation Inventory (Deci \& Ryan, 2011) were adjusted to assess

\footnotetext{
${ }^{1}$ Because of a printout mistake, the page containing the perceived competence subscale was left out from some questionnaires. As a result, only 320 out of the 606 students (52.81\% of the full sample, belonging to 16 classes) were assessed with respect to perceived competence.
}

students' competence need satisfaction with respect to mathematics or Greek language (e.g., "I think I am pretty good at mathematics (or Greek language)").

\subsubsection{Achievement goals}

We used the AGQ-R (Elliot \& Murayama, 2008) to assess students' mastery-approach goals ( 3 items, e.g., "My aim is to completely master the material presented in this class"), performance-approach goals (3 items, e.g., "My aim is to perform well relative to other students"), and performance-avoidance goals (3 items, e.g., "My aim is to avoid doing worse than other students").

\subsubsection{Perceived structure}

We used the Teacher Provision of Structure subscale of the Teacher as Social Context scale (Belmont, Skinner, Wellborn, \& Connell, 1988) to assess students' perceptions of structure. Four domains of teacher behavior were assessed: (a) contingency in terms of consistent and predictable interactions (6 items, e.g., "When we do something right, our teacher in [math/Greek language class] always lets us know"); (b) clarity of expectations (5 items, e.g., "We know what our teacher expects of us in [math/Greek language] class"); (c) help and support (5 items, e.g., "If we can't solve a problem, our teacher [in math/Greek language class] shows us different ways to try to"); and (d) adjustment and monitoring (5 items, e.g., "Our teacher [in math/Greek language class] makes sure we understand before he/she goes on").

\subsubsection{Learning strategies}

Three subscales, selected from the Motivated Strategies for Learning Questionnaire (Pintrich, Smith, Garcia, \& McKeachie, 1991), were used to assess students' learning strategies: critical thinking (5 items; e.g., "I treat the course material as a starting point and try to develop my own ideas about it"), meta-cognitive self-regulation (5 items; e.g., "When I become confused about something I'm reading for this class, I go back and try to figure it out), and effort-regulation (4 items; e.g., "Even when course materials are dull and uninteresting, I manage to keep working until I finish"). We created a composite score of learning strategies by averaging the respective scores of critical thinking, meta-cognitive self-regulation, and effort regulation.

\subsubsection{Positive and negative affect}

The short version of the Positive and Negative Affect Schedule (PANAS; Watson, Clark, \& Tellegen, 1988) was used to assess students' class-related positive (e.g., "I feel active") and negative (e.g., "I feel distressed") affect.

\subsubsection{Depressive feelings}

The Center for Epidemiologic Studies Short Depression Scale (CES-D; Radloff, 1977) was used to assess to what extent students experienced depressive symptoms and feelings during the last week prior to data collection. The CES-D contains ten items (e.g., "I felt depressed") answered on a 4-point Likert type scale $(0=$ Rarely, or none of the time [less than one day]; $4=$ All of the time [5-7 days]).

\subsubsection{Social desirability}

A short-form of the Marlow-Crowne Social Desirability Scale (Strahan \& Gerbasi, 1972) was used. This 10-item, true (1)/false (0) scale assesses students' propensity to respond in a socially desirable fashion (e.g., "I have never deliberately said something that hurt someone's feelings"). The ten responses were summed to yield a score reflecting students' social desirability inclination.

\section{Results}

We employed multilevel analysis to examine to what extent learning strategies and affect are explained at the student level by achievement goals, perceived structure, and social desirability responses (all 
group mean centered) and at the classroom level by aggregate scores of perceived classroom environment (grand mean centered). ${ }^{2}$ To test our mediation hypothesis, we also examined, after controlling for social desirability, whether perceived structure at the between-student level predicts perceived competence, which in turn predicts learning strategies and affect. For all the investigated outcomes, inspection of multivariate likelihood-ratio test favored a restricted (i.e., a fixed slopes) model over a model with randomly varying slopes (Raudenbush \& Bryk, 2002). Aligned with Raudenbush and Bryk (2002), we centered all the predictors at the student level as we were interested also in examining the cross-level interaction effects.

\subsection{Preliminary analyses}

Descriptive statistics and bivariate correlations for the full sample $(N=606)$ and for the reduced sample (due to missing values of perceived competence $N=320$ ), as well as the internal consistency of the scales, are presented in Table 1 . We first examined whether the aggregate scores of perceived structure at the classroom level differed between math and Greek language classes. The ANOVA showed no statistically significant differences in perceived structure at the classroom level between math and Greek language, $F(1,30)=2.34, p=$ .14. Apart from the nonsignificant ANOVA, inclusion of the type of class as a dummy variable in the multilevel models showed no significant effect. Therefore, both types of classes were analyzed as a whole.

In contrast, a MANOVA testing for gender differences was significant, Wilk's $\Lambda=.929, F(9,544)=4.65, p<.01$, multivariate $\eta^{2}=.07$ and the same was true in the reduced sample where perceived competence, as a proxy of competence need satisfaction, was also included in the list of the dependent variables: Wilk's $\Lambda=.931$, $F(10,282)=2.09, p<.05$, multivariate $\eta^{2}=.07$. Post-hoc ANOVA with Bonferroni correction showed statistically significant gender differences in positive affect $F(1,552)=12.62, p<.001, \eta^{2}=.02$ with males reporting higher levels of positive affect $(M=3.33, S D=0.82)$ than females $(M=3.06, S D=0.90)$. Therefore, gender was included as a covariate when we examined positive affect.

\subsection{Main and interaction effects}

\subsubsection{Competence need satisfaction}

Because of missing cases at level 1, the main analyses were based on a reduced sample ( $N=549 ; N=291$ for competence need satisfaction). Inspection of the intraclass correlation coefficient (ICC) in the unconditional model indicated that approximately $14.20 \%$ of the total variance was at the classroom level. Consistent with the theoretical assumptions that structure is linked with higher competence need satisfaction, the multilevel analysis showed that, after controlling for social desirability $\left(\gamma_{10 \text { [social desirability] }}=0.04, \mathrm{SE}=0.02, p<.05\right)$, perceived structure at both the student $\left(\gamma_{20[\text { between-student perceived structure }]}=0.32, \mathrm{SE}=0.07\right.$, $p<.01)$ and classroom level $\left(\gamma_{01[\text { between-classes structure] }}=0.87, \mathrm{SE}=\right.$ $0.12, p<.01$ ) were positively associated with perceived competence, explaining $9.56 \%$ and $92.06 \%$ of variance respectively ${ }^{3}$.

\footnotetext{
${ }^{2}$ We also tested the interaction hypothesis according to the multiple goal perspective (Barron \& Harackiewicz, 2001). None of the two-way interactions between mastery-approach and performance-approach goals were found to be statistically significant for any of the outcomes.

${ }^{3}$ Because the standard errors may be questionable due to the small number of level2 units, we also examined whether perceived structure, along with social desirability, predicts subject-related perceived competence through ordinary least squares. The regression model was significant, $\left(F[2,306]=31.32, p<01\right.$, adjusted $\left.R^{2}=.17\right)$ with perceived structure $(\beta=.38, p<.01)$, but not social desirability $(\beta=.09, p=.07)$, being a positive predictor of perceived competence.
}

\subsubsection{Learning strategies and affect}

The results are shown in Table 2. At the student level and in support of Hypothesis 1, perceived structure was related positively to positive affect and marginally to learning strategies, and negatively to negative affect and depressive feelings. Interestingly, these associations were observed after controlling for social desirability, which was also related positively to the most desired outcomes (i.e., learning strategies and positive affect) and negatively to the least desired outcomes (i.e., negative affect and depressive feelings).

Also in support of Hypothesis 3, mastery-approach and performanceapproach goals were positively associated with learning strategies and positive affect, with mastery-approach goals also being negatively related to depressive feelings. In contrast, performance-avoidance goals were related positively to the two negative affectivity outcomes and negatively (although marginally) to positive affect.

Further, in partial support of Hypothesis 4, a chi-square test confirmed that mastery-approach goals were more strongly related to learning strategies and marginally to positive affect than performance-approach goals $\left(\chi^{2}[1]=7.94, p<.01\right.$ and $\chi^{2}[1]=3.00$, $p=.08$, respectively).

At the classroom level and in support of Hypothesis 5, aggregated perceptions of structure were positive predictors of learning strategies and positive affect, and negative predictors of depressive feelings. This finding indicates that irrespective of the achievement goals that each student endorsed, students in well-structured as compared to ill-structured classrooms reported more effective learning strategies, higher positive affect, and less depressive feelings.

Regarding our research question, a statistically significant crosslevel interaction between performance-avoidance goals and aggregated perceived structure was found for both negative affect and depressive feelings. This interaction for negative affect is graphically displayed in Fig. 1. A test of simple slopes (see Bauer \& Curran, 2005; Preacher, Curran, \& Bauer, 2006) indicated that performanceavoidance goals were positive predictors of negative affect and depressive feelings in low (estimated beta $=0.17, t[30]=2.71, p<.01$ and estimated beta $=0.16, t[30]=4.47, p<.01$, respectively) and average structured classrooms (estimated beta $=0.10, t[30]=2.34, p<.05$ and estimated beta $=0.08, t[30]=3.03, p<.01$, respectively), but not in highly structured classrooms (estimated beta $=0.02, t[30]=0.33$, $p>.05$ and estimated beta $=0.00, t[30]=-0.02, p>.05$, respectively).

\subsection{Mediational analyses}

We tested Hypothesis 2 (mediation hypothesis) through multilevel analysis with the slopes allowed to vary randomly from class to class. Because of the limited number of level 2 units (see Footnote 1), only the relations at the student level were tested. Following Kenny, Bolger, and Korchmaros (2003) and the procedure described by Bauer, Preacher, and Gil (2006) we estimated the random indirect (i.e., $a b$ ) and total (i.e., $a b+c^{\prime}$ for student $i$ belonging in class $j$ ) relations and compared them to the direct relation $c_{i j}$ in a model with perceived structure being a sole predictor of each of the four outcomes (see Fig. 2).

Aligned with our mediation hypothesis and the argument provided by Skinner et al. (1998), we found competence need satisfaction to partly mediate the relation between perceived structure and the four outcomes as the direct relations, $c_{i j}$, decreased when perceived competence was also taken into account. Computation of the total effects (i.e., $c_{j}=c_{j}^{\prime}+a b_{j}+\sigma_{a b j}$ ) indicated that competence need satisfaction mediated $44.2 \%, 49.1 \%, 50.1 \%$, and $51.3 \%$ of the overall relation between perceived structure and learning strategies, positive affect, negative affect, and depressive feelings respectively, suggesting that competence need satisfaction partly mediated the relation between perceived structure and the studied outcomes at the betweenstudent level. 
Table 1

Means, standard deviations, zero-order correlations (two-tailed) and internal reliabilities of the measured variables of the study.

\begin{tabular}{|c|c|c|c|c|c|c|c|c|c|c|c|c|c|c|c|c|c|}
\hline Variables & 1 & 2 & 3 & 4 & 5 & 6 & 7 & 8 & 9 & 10 & 11 & 12 & 13 & 14 & 15 & 16 & 17 \\
\hline 1. Social desirability & .55 & & & & & & & & & & & & & & & & \\
\hline 2. Perceived competence ${ }^{a}$ & .17 & .76 & & & & & & & & & & & & & & & \\
\hline \multicolumn{18}{|l|}{ Students' goals } \\
\hline 3. Mastery-approach goals & .10 & .37 & .82 & & & & & & & & & & & & & & \\
\hline 4. Performance-approach goals & .01 & .30 & .40 & .88 & & & & & & & & & & & & & \\
\hline 5. Performance-avoidance goals & -.03 & .10 & .25 & .62 & .77 & & & & & & & & & & & & \\
\hline \multicolumn{18}{|l|}{ Perceived structure } \\
\hline 6. Contingency & .18 & .33 & .18 & .10 & .07 & .68 & & & & & & & & & & & \\
\hline 7. Expectations & .12 & .28 & .15 & .06 & .04 & .61 & .72 & & & & & & & & & & \\
\hline 8. Help and support & .18 & .36 & .22 & .15 & .11 & .67 & .66 & .79 & & & & & & & & & \\
\hline 9. Monitoring & .16 & .39 & .17 & .14 & .10 & .65 & .59 & .77 & .82 & & & & & & & & \\
\hline 10. Perceived structure (composite) & .19 & .40 & .21 & .13 & .10 & .83 & .81 & .91 & .89 & .92 & & & & & & & \\
\hline \multicolumn{18}{|l|}{ Self-regulated learning } \\
\hline 11. Critical thinking & .04 & .25 & .27 & .21 & .07 & .06 & .00 & .11 & .09 & .08 & .77 & & & & & & \\
\hline 12. Meta-cognitive regulation & .15 & .34 & .47 & .29 & .17 & .16 & .17 & .24 & .19 & .22 & .50 & .72 & & & & & \\
\hline 13. Effort regulation & .18 & .45 & .36 & .25 & .13 & .23 & .21 & .29 & .33 & .32 & .24 & .46 & .61 & & & & \\
\hline 14 Self-regulated learning (composite) & .15 & .43 & .47 & .32 & .16 & .18 & .15 & .27 & .25 & .25 & .77 & .84 & .71 & .82 & & & \\
\hline \multicolumn{18}{|l|}{ Affective correlates } \\
\hline 15. Positive affect & .20 & .62 & .28 & .21 & .06 & .15 & .14 & .22 & .22 & .22 & .34 & .35 & .32 & .44 & .87 & & \\
\hline 16. Negative affect & -.28 & -.35 & -.04 & .05 & .09 & -.19 & -.17 & -.18 & -.16 & -.20 & .02 & -.01 & -.16 & -.06 & -.31 & .84 & \\
\hline 17. Depression & -.29 & -.44 & -.13 & -.04 & .04 & -.17 & -.19 & -.16 & -.19 & -.21 & -.04 & -.13 & -.24 & -.17 & -.41 & .60 & .78 \\
\hline$M$ & 5.10 & 3.21 & 4.06 & 3.05 & 3.05 & 3.01 & 3.29 & 3.16 & 2.95 & 3.10 & 3.09 & 3.42 & 2.97 & 3.17 & 3.18 & 2.18 & 1.22 \\
\hline$S D$ & 2.09 & 0.83 & 0.90 & 1.11 & 1.07 & 0.78 & 0.79 & 0.97 & 1.07 & 0.78 & 0.81 & 0.73 & 0.87 & 0.62 & 0.88 & 0.84 & 0.60 \\
\hline
\end{tabular}

Note. Alpha coefficients are in the diagonal.

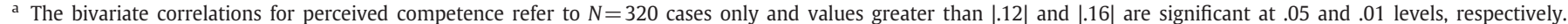
Correlations between the other variables of the study refer to the full sample $(N=606)$ and values greater than $|.08|$ and $|.12|$ are significant at .05 and .01 levels, respectively.

\section{Discussion}

Aligned with previous research (e.g., Taylor \& Ntoumanis, 2007), our study reveals the importance of properly structured learning environments. Similar to Sierens et al. (2009), our research indicates that the more teachers are perceived to communicate clear expectations and rules, monitor and adjust their teaching practices accordingly, behave in a contingent way, and provide the necessary help

Table 2

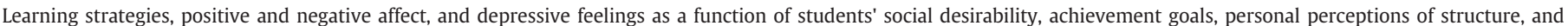
aggregate scores of perceived structure as a classroom characteristic $(\mathrm{N}=549)$

\begin{tabular}{|c|c|c|c|c|c|c|c|c|c|}
\hline \multirow[t]{2}{*}{ Fixed effects } & & \multicolumn{2}{|c|}{ Learning strategies } & \multicolumn{2}{|c|}{ Positive affect } & \multicolumn{2}{|c|}{ Negative affect } & \multicolumn{2}{|c|}{ Depressive feelings } \\
\hline & & $\gamma$ & SE & $\gamma$ & SE & $\gamma$ & SE & $\gamma$ & SE \\
\hline Intercept & $\gamma_{00}$ & 3.17 & $(0.04)$ & 3.02 & $(0.06)$ & 2.23 & $(0.06)$ & 1.23 & $(0.03)$ \\
\hline \multicolumn{10}{|l|}{ Between-student predictors } \\
\hline Social desirability & $\gamma_{10}$ & $0.30^{*}$ & $(0.12)$ & $0.59^{* *}$ & $(0.13)$ & $-0.84^{* *}$ & $(0.16)$ & $-0.61^{* *}$ & $(0.11)$ \\
\hline M-ap goals & $\gamma_{20}$ & $0.25^{* *}$ & $(0.03)$ & $0.24^{* *}$ & $(0.04)$ & -0.01 & $(0.04)$ & $-0.06^{*}$ & $(0.03)$ \\
\hline P-ap goals & $\gamma_{30}$ & $\mathbf{0 . 1 1}^{* *}$ & $(0.03)$ & $0.13^{*}$ & $(0.05)$ & -0.03 & $(0.03)$ & -0.05 & $(0.03)$ \\
\hline P-av goals & $\gamma_{40}$ & -0.04 & $(0.03)$ & $-0.07^{\dagger}$ & $(0.03)$ & $0.10^{* *}$ & $(0.03)$ & $0.08^{* *}$ & $(0.03)$ \\
\hline Perceived structure & $\gamma_{50}$ & $0.08^{\dagger}$ & $(0.04)$ & $0.33^{* *}$ & $(0.07)$ & $-0.18^{* *}$ & $(0.06)$ & $-0.09^{*}$ & $(0.04)$ \\
\hline Gender & $\gamma_{60}$ & - & & $0.33^{* *}$ & $(0.07)$ & - & & - & \\
\hline \multicolumn{10}{|l|}{ Between-classroom predictors } \\
\hline Classroom structure & $\gamma_{01}$ & $0.34^{*}$ & $(0.13)$ & $0.49^{* *}$ & $(0.16)$ & $-0.25^{\dagger}$ & $(0.15)$ & $-0.21^{*}$ & $(0.08)$ \\
\hline \multicolumn{10}{|l|}{ Student $\times$ between-classroom interactions } \\
\hline Social desirability $\times$ classroom structure & $\gamma_{11}$ & 0.17 & $(0.34)$ & -0.50 & $(0.37)$ & -0.65 & $(0.48)$ & 0.06 & $(0.32)$ \\
\hline M-ap goals $\times$ classroom structure & $\gamma_{21}$ & -0.01 & $(0.11)$ & 0.13 & $(0.15)$ & 0.16 & $(0.13)$ & 0.02 & $(0.08)$ \\
\hline P-ap goals $\times$ classroom structure & $\gamma_{31}$ & -0.10 & $(0.07)$ & -0.14 & $(0.10)$ & $-0.13^{\dagger}$ & $(0.07)$ & 0.00 & $(0.08)$ \\
\hline P-av goals $\times$ classroom structure & $\gamma_{41}$ & -0.02 & $(0.07)$ & 0.14 & $(0.11)$ & $-0.20^{*}$ & $(0.09)$ & $-0.20^{* *}$ & $(0.07)$ \\
\hline Perceived structure $\times$ classroom structure & $\gamma_{51}$ & 0.02 & $(0.15)$ & -0.11 & $(0.16)$ & 0.08 & $(0.20)$ & 0.00 & $(0.12)$ \\
\hline Gender $\times$ classroom structure & $\gamma_{61}$ & - & & -0.11 & $(0.16)$ & - & & - & \\
\hline \multicolumn{4}{|l|}{ Random effects } & \multicolumn{6}{|c|}{ Variance components } \\
\hline Intercept & $u_{o j}$ & 0.03 & & 0.05 & & 0.08 & & 0.01 & \\
\hline Within classroom variance & $r_{i j}$ & 0.26 & & 0.60 & & 0.57 & & 0.31 & \\
\hline \multicolumn{10}{|l|}{ Auxiliary statistics } \\
\hline ICC & & .11 & & .08 & & .11 & & .04 & \\
\hline \multicolumn{10}{|l|}{$\%$ variance explained at the } \\
\hline Student level & & $24.35 \%$ & & $15.16 \%$ & & $9.10 \%$ & & $9.16 \%$ & \\
\hline Classroom level & & $25.70 \%$ & & $26.57 \%$ & & $5.07 \%$ & & $27.70 \%$ & \\
\hline
\end{tabular}

Note. $\mathrm{M}$-ap = mastery-approach; P-ap= performance-approach; P-av= performance-avoidance. Gender coefficient (dummy-coded: $0=$ females; $1=$ males) was uncentered.

+ $p \leq .10$.

$\dagger p=.06$.

$* p<.05$.

** $p<.01$. 


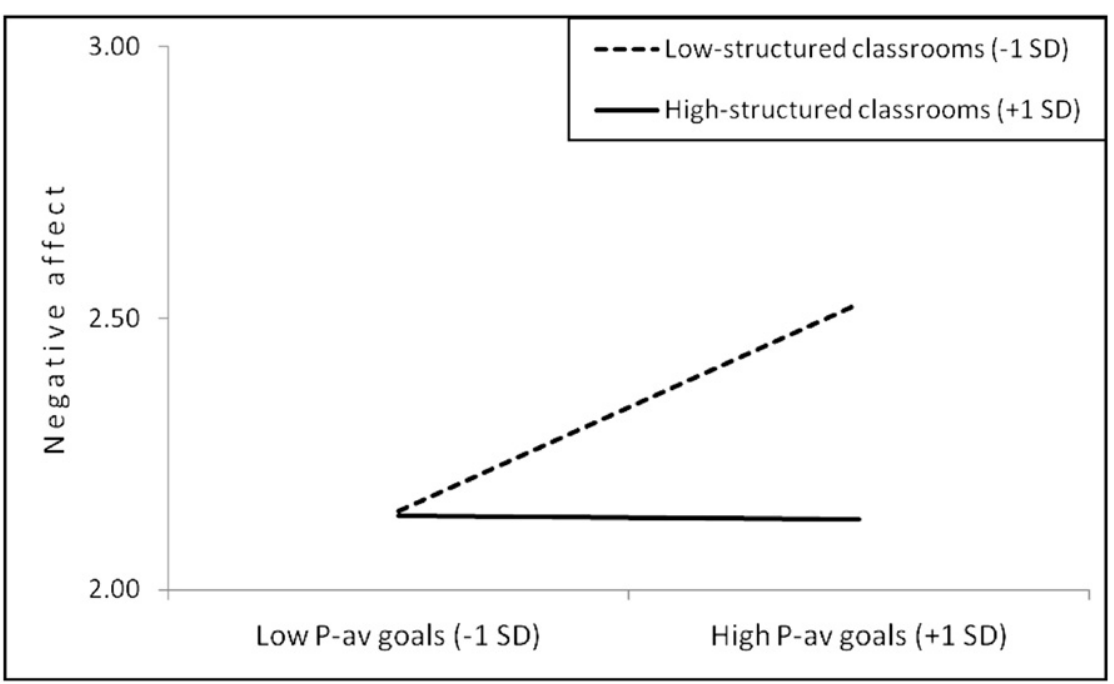

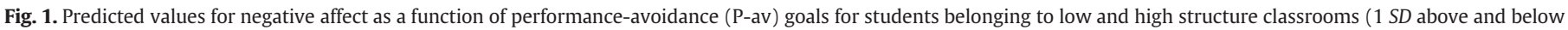
the mean, respectively).

and support to their students, the more these students use effective learning strategies and experience positive feelings. As our analyses indicate, structure can be beneficial both at the student and the classroom level, suggesting that the relations between perceived structure and outcomes operate quite independently at these two levels. Thus, students may experience more desired affectivity if they perceive the teacher to provide structure (within-class effect), irrespective of whether they find themselves in a classroom characterized by low or high structure. Concomitantly, students who perceive the teacher to be rather chaotic will nevertheless experience more positive affectivity if they belong to a well-structured classroom compared to students with similar perceptions belonging to a non-structured classroom.

Well-structured learning environments seem to facilitate students' use of effective learning strategies and to promote positive schoolrelated affectivity, presumably because in such classrooms students a priori know the rules and the procedures they need to follow to achieve their goals. In such environments, students have more opportunities to exercise their skills and to competently engage in required activities because the learning environment becomes predictable and helpful when occasion arises (Skinner et al., 1998). Indeed, as the present analyses indicated, perceived competence seems to be the mediating mechanism through which structure becomes beneficial for students. It appears that certain aspects of structure like clear and consistent guidelines, predictability, and reasonable expectations contribute to competence need satisfaction (Farkas \& Grolnick, 2010), which in turn enhances self-regulated learning and positive affectivity. In contrast, unclarified misconceptions or uncertainties seem to be demotivating because they generate feelings of incompetence (Wijnia, Loyens, \& Derous, 2011).

It should be underscored however, that well-structured learning environments are more beneficial when teachers set rules, monitor students' behaviors and progress, and provide help and support in an autonomy-supportive rather than controlling way (Jang et al., 2010; see also Soenens \& Vansteenkiste, 2010). Providing structure in an autonomy-supportive way means that the teacher sets the rules and communicates to students what he or she expects from them by taking students' perspective and acknowledging their feelings. As Sierens et al. (2009) have recently indicated, provision of structure is positively associated with effective cognitive strategies and self-regulation only when this structure coexists with an autonomy-supportive classroom environment. Therefore, although this and previous research have shown that perceived structure is associated with desirable outcomes, it is likely because provision of structure co-occurs with provision of autonomy support (Jang et al., 2010; Sierens et al., 2009; Vansteenkiste et al., in press), and it is highly likely that structure will be harmful if it is provided in a coercive manner (Deci \& Ryan, 2000). Future studies need to concurrently examine the independent and joint effects of structure, autonomysupportive learning climate, and personal achievement goals.

Consistent with the recent operationalization of achievement goals (Elliot \& Murayama, 2008), this research indicates that personal mastery-approach goals, and to a lesser extent performanceapproach goals, are linked with positive outcomes, whereas performance-avoidance goals are linked with negative affectivity. Interestingly, these findings were observed after taking into account students' socially desirable response. These findings complement previous ones in two noteworthy ways. First, they show that even if one detaches the underlying reasons (i.e., fear of failure) from the definition of performance-avoidance goals (and thus assess them as pure aims-see Elliot \& Murayama, 2008), performance-avoidance goals seem to be maladaptive compared to approach goals. Although performance-avoidance goals did not (negatively) predict learning strategies or positive affect, these goals alone positively predicted negative affectivity. It seems that the more students focus on avoiding being outperformed by their classmates, the more negative affectivity they experience. Second, similarly to recent studies (e.g., Diseth \& Kobbeltvedt, 2010; Liem, Lau, \& Nie, 2008; Linnenbrink, 2005; Pekrun, Elliot, \& Maier, 2009) performance-approach goals were positively related to learning strategies and positive affect, yet their relation to these outcomes was weaker compared to the respective relation of mastery-approach goals. Contributing to the ongoing debate about whether performance-approach goals are adaptive, our study indicates that performance-approach goals may not be as harmful as it had been originally thought, partly because of the recent conceptualization of performance-approach goals which detaches reasons from aims (see Elliot, 2005; Vansteenkiste et al., 2010). Even so, however, performance-approach goals appear to be less beneficial compared to mastery-approach goals. In practice, this means that teachers will do better if they encourage their students to pursue mastery-approach goals instead of performance-approach goals, as the former appear to offer more benefits, including buffering depressive symptoms.

A notable finding in this study concerns the moderating role of structure on the relationship between performance-avoidance goals and negative affectivity. As our results imply, provision of structure 

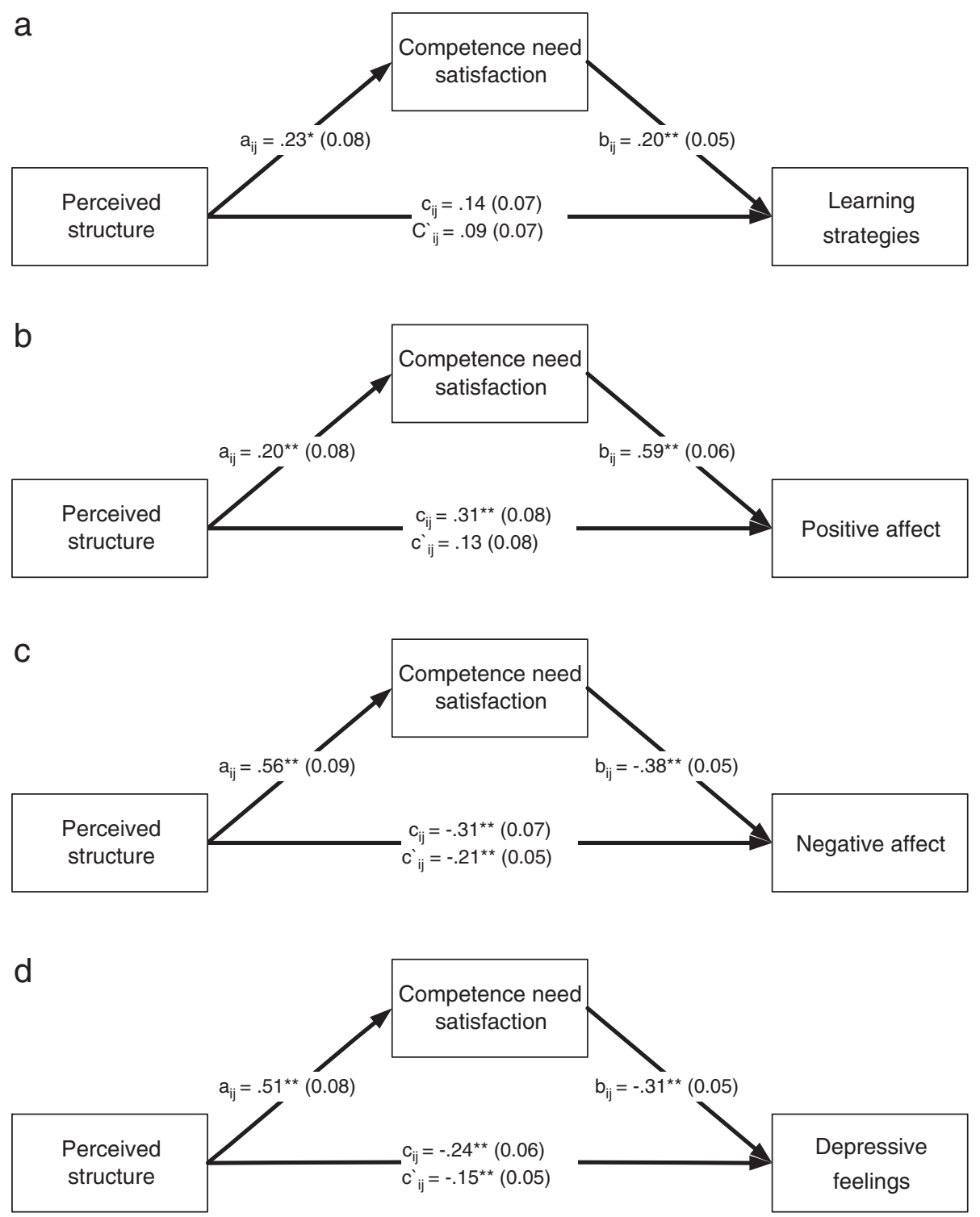

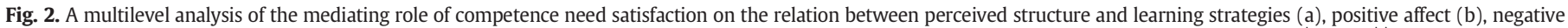
affect (c), and depressive feelings (d) at the student level. All path coefficients (intercept slopes) are standardized with standards errors in parentheses. ${ }^{*} p<.05$. ${ }^{* *} p<.01$.

may emotionally shield those students who are mainly concerned with avoiding performing worse than others, presumably because in such classrooms students feel more secure, certain, and competent, in spite of their rather maladaptive achievement strivings. Nevertheless, the moderating role of structure was found to concern negative affectivity but not learning strategies or positive affect. Is this because structured classrooms selectively protect students who endorse performanceavoidance goals from experiencing negative emotions? Obviously, future research needs to examine thoroughly whether structure differentially influences the relation of performance-avoidance goals to a broader set of outcomes.

\subsection{Limitations}

The present study contains several limitations. First, as it is cross-sectional, no inferences can be made about the direction of causality. Second, it is based on the same source of informants (i.e., the students) and thus a potential bias due to a common method variance could have distorted our findings (although we tried to control for such a bias by taking into account students' tendency to respond in a socially desirable manner). Third, other aspects of the learning environment, mainly autonomy support and its associated autonomy need satisfaction, have been overlooked. Finally, the social desirability scale yielded marginal internal consistency.

\section{Conclusion}

The more a teacher is perceived by his or her students to set clear rules, interact with them in a consistent way, provide help and support, monitor students' progress, and adjust his or her teaching accordingly, the more the students feel competent. They feel more competent because the learning environment becomes predictable which fosters more effective learning strategies and the experience of more positive affect. Such a learning environment seems to protect in particular students who endorse avoidance goals from experiencing negative feelings.

\section{References}

Barron, K. E., \& Harackiewicz, J. M. (2001). Achievement goals and optimal motivation: Testing multiple goal models. Journal of Personality and Social Psychology, 80, 706-722. http://dx.doi.org/10.1037//0022-3514.80.5.706. 
Barron, K. E., \& Harackiewicz, J. M. (2003). Revisiting the benefits of performanceapproach goals in the college classroom: Exploring the role of goals in advanced college students. International Journal of Educational Research, 39, 357-374. http://dx.doi.org/ 10.1016/j.ijer.2004.06.004.

Bauer, D. J., \& Curran, P. J. (2005). Probing interactions in fixed and multilevel regression: Inferential and graphical techniques. Multivariate Behavioral Research, 40, 373-400. http://dx.doi.org/10.1207/s15327906mbr4003_5.

Bauer, D. J., Preacher, K. J., \& Gil, K. M. (2006). Conceptualizing and testing random indirect effects and moderated mediation in multilevel models: New procedures and recommendations. Psychological Methods, 11, 142-163. http://dx.doi.org/10.1037/ 1082-989X.11.2.142.

Belmont, M., Skinner, E., Wellborn, J., \& Connell, J. (1988). Teacher as social context. A measure of student perceptions of teacher provision of involvement, structure, and autonomy support (Tech. Rep. No. 102). Rochester, New York: University of Rochester.

Brophy, J. (2005). Goal theorists should move on from performance goals. Educational Psychologist, 40, 167-176. http://dx.doi.org/10.1207/s15326985ep4003_3.

Ciani, K. D., \& Sheldon, K. M. (2010). Evaluating the mastery-avoidance goal construct: A study of elite college players. Psychology of Sport and Exercise, 11, 127-132. http://dx.doi.org/10.1016/j.psychsport.2009.04.005.

Deci, E. L., \& Ryan, R. M. (2000). The "What" and "Why" of goal pursuits: Human needs and the self determination of behavior. Psychological Inquiry, 11, 227-268. http://dx.doi.org/ 10.1207/S15327965PLI1104_01.

Deci, E. L., \& Ryan, R. M. (2011). Intrinsic motivation inventory. Retrieved from http:// www.psych.rochester.edu/SDT/measures/IMI_scales.php

Diseth, Å., \& Kobbeltvedt, T. (2010). A mediation analysis of achievement motives, goals, learning strategies, and academic achievement. British Journal of Educational Psychology, 80, 671-687. http://dx.doi.org/10.1348/000709910X492432.

Elliot, A. J. (1999). Approach and avoidance motivation and achievement goals. Educational Psychologist, 34, 169-189. http://dx.doi.org/10.1207/s15326985ep3403_3.

Elliot, A. J. (2005). A conceptual history of the achievement goal construct. In A. J. Elliot, \& C. S. Dweck (Eds.), Handbook of competence and motivation (pp. 52-72). New York: Guilford.

Elliot, A. J., \& McGregor, J. A. (2001). A $2 \times 2$ achievement goal framework. Journal of Personality and Social Psychology, 80, 501-519. http://dx.doi.org/10.1016/ j.psychsport.2005.08.012.

Elliot, A. J., \& Moller, A. C. (2003). Performance-approach goals: Good or bad forms of regulation. International Journal of Educational Research, 39, 339-356. http://dx.doi.org/ 10.1016/j.ijer.2004.06.003

Elliot, A. J., \& Murayama, K. (2008). On the measurement of achievement goals: Critique, illustration, and application. Journal of Educational Psychology, 100, 613-628. http://dx.doi.org/10.1037/0022-0663.100.3.613.

Farkas, M. S. \& Grolnick, W. S. (2010). Examining the components and concomitants of parental structure in the academic domain. Motivation and Emotion, 34, 266-279. http://dx.doi.org/10.1007/s11031-010-9176-7.

Harackiewicz, J. M., Durik, A. M., Barron, K. E., Linnenbrink-Garcia, L., \& Tauer, J. M. (2008). The role of achievement goals in the development of interest: Reciprocal relations between achievement goals, interest, and performance. Journal of Educational Psychology, 100, 105-122. http://dx.doi.org/10.1037/0022-0663.100.1.105.

Hulleman, C. S., Schrager, S. M., Bodmann, S. M., \& Harackiewicz, J. M. (2010). A meta-analytic review of achievement goal measures: Different labels for the same constructs or different constructs with similar labels? Psychological Bulletin, 136, 422-449. http://dx.doi.org/10.1037/a0018947.

Jang, H., Reeve, J., \& Deci, E. L. (2010). Engaging students in learning activities: It's not autonomy support or structure, but autonomy support and structure. Journal of Educational Psychology, 102, 588-600. http://dx.doi.org/10.1037/a0019682.

Kaplan, A., Middleton, M. J., Urdan, T., \& Midgley, C. (2002). Achievement goals and goal structures. In C. Midgley (Ed.), Goals, goal structures and patterns of adaptive learning (pp. 21-53). Mahwah, NJ: Lawrence Erlbaum.

Kenny, D. A., Bolger, N., \& Korchmaros, J. D. (2003). Lower level mediation in multilevel models. Psychological Methods, 8, 115-128. http://dx.doi.org/10.1037/1082-989X. 8.2.115

Liem, A. D., Lau, S., \& Nie, Y. (2008). The role of self-efficacy, task value, and achievement goals in predicting learning strategies, task disengagement, peer relationship, and achievement outcome. Contemporary Educational Psychology, 33, 486-512. http://dx.doi.org/10.1016/j.cedpsych.2007.08.001.
Linnenbrink, E. A. (2005). The dilemma of performance-approach goals: The use of multiple goal contexts to promote students' motivation and learning. Journal of Educational Psychology, 97, 197-213. http://dx.doi.org/10.1037/0022-0663.97.2.197.

Pekrun, R., Elliot, A. J., \& Maier, M. A. (2009). Achievement goals and achievement emotions: Testing a model of their joint relations with academic performance. Journal of Educational Psychology, 101, 115-135. http://dx.doi.org/10.1037/a0013383.

Pintrich, P. R., Smith, D., Garcia, T., \& McKeachie, W. J. (1991). A manual for the use of the Motivated Strategies for Learning Questionnaire (MSLO). Ann Arbor, MI: National Center for Research to Improve Postsecondary Teaching and Learning, University of Michigan.

Preacher, K. J., Curran, P. J., \& Bauer, D. J. (2006). Computational tools for probing interactions in multiple linear regression, multilevel modeling and latent curve analysis. Journal of Educational and Behavioral Statistics, 31, 437-448. http://dx.doi.org/ 10.3102/10769986031004437.

Radloff, L. S. (1977). The CES-D scale: A self-report depression scale for research in the general population. Applied Psychological Measurement, 1, 385-401.

Raudenbush, S. W., \& Bryk, A. S. (2002). Hierarchical linear models: Applications and data analysis methods (2nd edition). Newbury Park, CA: Sage.

Reeve, J. (2006). Teachers as facilitators: What autonomy-supportive teachers do and why their students benefit. The Elementary School Journal, 106, 225-236. http: //dx.doi.org/10.1086/501484

Seidel, T., Rimmele, R., \& Prenzel, M. (2005). Clarity and coherence of lesson goals as a scaffold for student learning. Learning and Instruction, 15, 539-556. http://dx.doi.org/ 10.1016/j.learninstruc.2005.08.004.

Sierens, E., Vansteenkiste, M., Goossens, L., Soenens, B., \& Dochy, F. (2009). The interactive effect of perceived teacher autonomy-support and structure in the prediction of self-regulated learning. British Journal of Educational Psychology, 79, 57-68. http://dx.doi.org/10.1348/000709908X304398.

Skinner, E. A. \& Belmont, M. J. (1993). Motivation in the classroom: Reciprocal effects of teacher behavior and student engagement across the school year. Journal of Educational Psychology, 85, 571-581. http://dx.doi.org/10.1037/0022-0663.85.4.571.

Skinner, E. A., Zimmer-Gembeck, M. J., \& Connell, J. P. (1998). Individual differences and the development of perceived control. Monographs of the Society for Research in Child Development, 63(2-3) Whole No. 204).

Soenens, B., \& Vansteenkiste, M. (2010). A theoretical upgrade of the concept of parental psychological control: Proposing new insights on the basis of self-determination theory. Developmental Review, 30, 74-99. http://dx.doi.org/10.1016/j.dr.2009.11.001.

Strahan, R., \& Gerbasi, K. C. (1972). Short, homogeneous versions of Marlowe-Crowne social desirability scale. Journal of Clinical Psychology, 28, 191-193. http://dx.doi.org/ 10.1002/1097-4679(197204)28:2<191::AID-JCLP2270280220>3.0.CO;2-G.

Taylor, I. M., \& Ntoumanis, N. (2007). Teacher motivational strategies and student self-determination in physical education. Journal of Educational Psychology, 99, 747-760. http://dx.doi.org/10.1037/0022-0663.99.4.747.

Tessier, D., Sarrazin, P., \& Ntoumanis, N. (2010). The effect of an intervention to improve newly qualified teachers' interpersonal style, students motivation and psychological need satisfaction in sport-based physical education. Contemporary Educational Psychology, 35, 242-253. http://dx.doi.org/10.1016/j.cedpsych.2010. 05.005.

Urdan, T., \& Schoenfelder, E. (2006). Classroom effects on student motivation: Goal structures, social relationships, and competence beliefs. Journal of School Psychology, 44, 331-349. http://dx.doi.org/10.1016/j.jsp. 2006.04.003.

Vansteenkiste, M., Sierens, E., Goossens, L., Soenens, B., Dochy, F., Mouratidis, A., et al. (in press). Identifying configurations of perceived teacher autonomy support and structure: Associations with self-regulated learning, motivation, and problem behavior. Learning and Instruction.

Vansteenkiste, M., Smeets, S., Lens, W., Soenens, B., Matos, L., \& Deci, E. L. (2010) Autonomous and controlled regulation of performance-approach goals: Their relations to perfectionism and educational outcomes. Motivation and Emotion, 34 333-353. http://dx.doi.org/10.1007/s11031-010-9188-3.

Watson, D., Clark, L. A., \& Tellegen, A. (1988). Development and validation of brief measures of positive and negative affect: The PANAS scales. Journal of Personality and Social Psychology, 54, 1063-1070. http://dx.doi.org/10.1037/0022-3514.54.6.1063.

Wijnia, L., Loyens, S. M., \& Derous, E. (2011). Investigating effects of problem-based versus lecture-based learning environments on student motivation. Contemporary Educational Psychology, 36, 101-113. http://dx.doi.org/10.1016/j.cedpsych.2010.11.003. 